\title{
Descrição dos estágios imaturos e notas sobre a biologia de Phloea subquadrata (Heteroptera, Phloeidae) ${ }^{1}$
}

\author{
Jorge L. C. Bernardes ${ }^{2,5}$, Jocélia Grazia ${ }^{2,5}$, Aline Barcellos $^{3}$ \& Adriana T. Salomão ${ }^{4}$ \\ 1. Contribuição ${ }^{\circ} 471$ do Departamento de Zoologia da UFRGS. \\ 2. Setor de Entomologia Sistemática, Departamento de Zoologia, Instituto de Biociências, Universidade Federal do Rio Grande do Sul, Av. \\ Bento Gonçalves, 9500, Bloco IV, prédio 43435.2, 91501-970 Porto Alegre, RS, Brasil. (jorgecabeleira@gmail.com; jocelia@ufrgs.br) \\ 3. Museu de Ciências Naturais, Fundação Zoobotânica do Rio Grande do Sul, Caixa Postal 1188, 90001-970 Porto Alegre, RS, Brasil. \\ (alinebar@fzb.rs.gov.br) \\ 4. Programa de Pós-Graduação em Ecologia, Universidade Estadual de Campinas, Instituto de Biologia, Departamento de Zoologia, Caixa \\ Postal 6109, 13083-970 Campinas, SP, Brasil. Bolsista FMB. (asalomao@unicamp.br) \\ 5. Bolsista CNPq.
}

ABSTRACT. Description of immature stages and notes on the biology of Phloea subquadrata (Heteroptera, Phloeidae). The eggs and five nymphal instars of Phloea subquadrata Spinola, 1837 are described and illustrated. Three new host plants are registered, and data on the development and biology of the insect are provided and discussed.

KEYWORDS. Immatures, external morphology, biology, neotropics, Phloeidae.

RESUMO. Os ovos e os cinco estádios ninfais de Phloea subquadrata Spinola, 1837 são descritos e ilustrados. Três novas plantas hospedeiras são registradas, e dados sobre o desenvolvimento e a biologia do inseto são apresentados e discutidos.

PALAVRAS-CHAVE. Imaturos, morfologia externa, biologia, neotrópicos, Phloeidae.

O estudo dos estágios imaturos de insetos contribui de forma decisiva para o conhecimento de um táxon, facilitando sua identificação, auxiliando a compreender sua biologia e relações ecológicas, e servindo como importante ferramenta na sistemática do grupo ao qual pertence (BRAILOVSKY et al., 1992). O entendimento mais detalhado dos insetos imaturos e de sua relação com os adultos possibilita avaliar melhor a existência de variações e convergências entre grupos (RITCHER, 1972). Além disso, em muitas espécies, a alimentação é realizada principalmente na fase larval e os adultos são destinados primariamente à reprodução (STEHR, 1991); em espéciespraga, por exemplo, imaturos podem causar às plantas hospedeiras danos maiores que os adultos (BRAILOvSKY et al., 1992).

Os insetos pertencentes à família Phloeidae são todos ocorrentes na Região Neotropical. No Brasil, distribuem-se na Mata Atlântica lato sensu, estendendose até a região amazônica (Lent \& JuRberg, 1965). Apresentam hábito fitófago (SchuH \& Slater, 1995), provavelmente alimentando-se da seiva de plantas arbóreas, porém não há registros de danos às plantas utilizadas. Phloeidae inclui os gêneros Phloea Lepeletier \& Serville, 1825, com Phloea corticata (Drury, 1773) e Phloea subquadrata Spinola, 1837, e Phloeophana Kirkaldy, 1908, monotípico, com Phloeophana longirostris (Spinola, 1837). Os insetos desta família apresentam o corpo achatado, com expansões lobadas e foliáceas, olhos divididos em uma porção dorsal e outra ventral, e antenas triarticuladas, inseridas anteriormente aos olhos e encobertas pelas expansões cefálicas. As principais diferenças entre os gêneros incluem a forma dos lobos cefálicos e o comprimento do rostro e do escutelo, além da genitália de ambos os sexos, que difere no formato do pigóforo e parâmeros no macho e das placas genitais e receptaculum seminis na fêmea.

Os fleídeos vivem sobre troncos de árvores (LENT \& JURBERG, 1965), as quais se assemelham na coloração e forma, além da textura (J. Vasconcellos Neto \& A. T. Salomão, dados não-publicados). As fêmeas exercem o cuidado da prole permanecendo sobre os ovos e carregando as ninfas dos primeiros instares aderidas ao abdome, ventralmente (Schiödte, 1845 e Magalhães, 1909 apud Leston, 1953; Lent \& JuRberg, 1966). Neste grupo, o cuidado parental foi discutido por TALLAMY \& SChAefER (1997) e Guilbert (2003).

A forma peculiar destes insetos, associada aos seus hábitos singulares, tem atraído a atenção de muitos pesquisadores (LESTON, 1953; LENT \& JURBERG, 1965, 1966; GuIlBERT, 2003). Entretanto, pouco ainda foi esclarecido sobre o grupo (GUILBERT, 2003). LENT \& JURBERG (1965) descreveram a morfologia externa e interna (genitália) dos adultos e forneceram dados de distribuição e plantas hospedeiras para as três espécies conhecidas de Phloeidae. Somente para P. longirostris foi realizado um estudo sucinto da morfologia externa dos imaturos (LENT \& JURBERG, 1966).

Esta contribuição objetiva descrever e ilustrar o ovo e os cinco instares ninfais de P. subquadrata. Além disso, são apresentados novos registros de plantas hospedeiras e dados sobre o desenvolvimento dos estágios imaturos. Este é o primeiro estudo a fornecer uma descrição detalhada de ninfas de Phloeidae e informações sobre o ciclo de vida de uma das espécies. 


\section{MATERIAL E MÉTODOS}

Ninfas de $2^{\circ}$ a $5^{\circ}$ instares de $P$. subquadrata foram coletadas em janeiro de 2003 na Serra do Japi, Jundiaí, Estado de São Paulo (2311'S, 46 $52^{\circ}$ 'W). Adultos com ovos e ninfas de $1^{\circ}$ instar foram obtidos em dezembro de 2004 na propriedade do Colégio N. Sra. das Graças, Viamão, RS (3008'S, 51 $\left.{ }^{\circ} 05^{\prime} \mathrm{W}\right)$. Exemplares adultos utilizados para comparação com o material coletado pertencem à coleção entomológica do Departamento de Zoologia da Universidade Federal do Paraná, Curitiba (DZUP). Todos os imaturos e adultos capturados foram fixados em álcool etílico $70 \%$ e depositados na coleção do Setor de Entomologia Sistemática do Departamento de Zoologia da UFRGS, Porto Alegre (UFRG). As imagens foram capturadas digitalmente e as ilustrações elaboradas com auxílio de câmara-clara acoplada a estereomicroscópio. A descrição da coloração foi baseada em exemplares fixados. Os dados morfométricos foram adaptados de MATESCO et al. (2003) e os valores mínimo e máximo apresentados em milímetros: comprimento total (CT), comprimento da cabeça (CC), comprimento do tórax (CTO), distância interocular (DI), largura do abdome (LA), largura do tórax (LT), largura da cabeça (LC), comprimento do rostro (CR) e artículos antenais I a III (respectivamente, I, II, III).

Duas posturas com ovos parasitados (A. T. Salomão \& J. Vasconcellos Neto, dados não-publicados) e nãoparasitados intactos foram coletadas na Serra do Japi para verificar se as ninfas eclodiriam sem a presença da fêmea. As posturas foram mantidas em placas de Petri e submetidas às condições ambientais de laboratório.

A duração do estágio de ovo foi estimada através de observações semanais realizadas na Serra do Japi, no período entre janeiro e março de 2004. Para estimar o tempo de desenvolvimento ninfal, cinco grupos de ninfas de segundo estádio $(\mathrm{N}=136)$ foram acompanhados semanal ou quinzenalmente entre fevereiro de 2004 e fevereiro de 2005. As observações foram realizadas no campo, dada a impossibilidade de manter uma criação de fleídeos em laboratório.

\section{RESULTADOS E DISCUSSÃO}

Ovo (Figs. 1, 2, 13). Alongado e não-operculado, apresenta 15 a 18 processos aeromicropilares (estruturas descritas por Wolf et al., 2002). Coloração branco-leitosa, ligeiramente ocre-clara no período final de incubação. Comprimento, 2,41-2,61; largura, 1,44-1,52 ( $=22)$.

Primeiro instar (Figs. 3, 4). Forma geral ovalada, levemente achatada dorso-ventralmente. Maior largura do corpo no nível do segmento abdominal III. Coloração geral esbranquiçada logo após a eclosão, tornando-se ocre-clara com o decorrer do desenvolvimento. Pontuações de coloração castanha esparsas no tórax e nas placas dorsais. Jugas com expansões foliáceas laterais recobrindo o artículo antenal I. Antenas trissegmentadas, com o artículo III levemente fusiforme, coberto de pêlos finos. Olhos compostos vermelhos, ocelos ausentes. Rostro alcança o urosternito IV. Tórax ocre-escuro, com poucas pontuações, os três segmentos bem definidos, com expansões evidentes nas margens do pro- e mesonoto. Pernas com tonalidade mais escura a partir da tíbia. Abdome destituído de expansões foliáceas, dorsalmente ocre uniforme, sem manchas, com exceção das suturas e pseudo-suturas amareloesbranquiçadas. Placas laterais e dorsais ocre-escuras, estas últimas com pontuações escassas, dotadas de aberturas das glândulas odoríferas no limite entre os segmentos III-IV, IV-V e V-VI. Ventre ocre-claro. Espiráculos (Fig. 4) nos segmentos III a VIII castanhoescuros, quase negros. Um par de tricobótrios (Fig. 4) nos segmentos III a VII, dispostos em diagonal na linha dos espiráculos, o anterior sobre um pequeno tubérculo.

Medidas $(\mathrm{N}=6)$. CT, 3,78 - 3,93; CC, 0,85 - 0,97; CTO, 0,81 - 0,97; DI, 0,72 - 0,76; LA, 2,03 - 2,28; LT, 1,69 1,82; LC, 1,14 - 1,97; CR, 1,99 - 2,18; I, 0,22 - 0,26; II, 0,19 0,20; III, 0,34-0,38.

Segundo instar (Figs. 5, 6). Forma geral mais ovalada e muito mais deprimida do que no $1^{\circ}$ instar. Expansões foliáceas mais desenvolvidas, manchas e pontuações castanho-escuras espalhadas pela superfície dorsal e em maior número que no $1^{\circ}$ estádio, conferindo o aspecto críptico característico da família (Fig. 5). Coloração geral castanha. Placas cefálicas em forma de leque devido às expansões foliáceas laterais, que cobrem quase totalmente as antenas, deixando exposta apenas a metade do artículo III. Jugas expandidas, mais longas que o clípeo e convergentes, quase contíguas anteriormente; pontuações em maior número do que no instar anterior. Pêlos concentrados no artículo antenal III. Olhos oblíquos, vermelhos e divididos dorso-ventralmente por uma faixa negra; ocelos ausentes. Rostro alcança ou ultrapassa o segmento VI. Tórax castanho-escuro, com pontuações mais escuras do que no primeiro instar. Metanoto abreviado lateralmente pelas expansões do segmento abdominal I. Abdome castanho; segmentos, com exceção do X, com expansões foliáceas. Abertura das glândulas odoríferas situadas sobre as placas dorsais, junto às suturas, entre os segmentos III-IV, IV-V e V-VI. Ventralmente, coloração semelhante à do $1^{\circ}$ instar, apenas mais escura. Espiráculos (Fig. 6) nos segmentos II a VIII. Tricobótrios (Fig. 6) dispostos longitudinalmente e externos à linha dos espiráculos, o tricobótrio anterior sobre um pequeno tubérculo.

Medidas ( $\mathrm{N}=6)$. CT, 6,48 - 7,04; CC, 1,70 - 1,90; CTO, 1,44 - 1,60; DI, 1,32 - 1,40; LA, 4,00 - 4,48; LT, 3,52 3,92; LC, 2,52 - 2,76; CR, 5,26 - 5,75; I, 0,40 - 0,64; II, 0,32 0,$40 ;$ III, $0,52-5,75$.

Terceiro instar (Figs. 7, 8). Forma geral achatada e ovalada (Fig. 7), com coloração semelhante à dos adultos e maior concentração de pontuações e manchas. Jugas justapostas ou sobrepostas diante do clípeo. Pontuações verde-metálicas na cabeça entre o clípeo e os olhos. Rostro alcança o segmento abdominal VI. Expansões foliáceas mais desenvolvidas e manchadas; pontuações castanho-escuras, distribuídas na superfície dorsal, formando semicírculos concêntricos. Bordo posterior do mesonoto projetado em direção posterior, dando início à formação do escutelo. Metanoto e segmento abdominal I encurtados lateralmente. Expansões do segmento abdominal IX tocam-se ou se sobrepõem diante do segmento X. Espiráculos como descrito no instar anterior. 

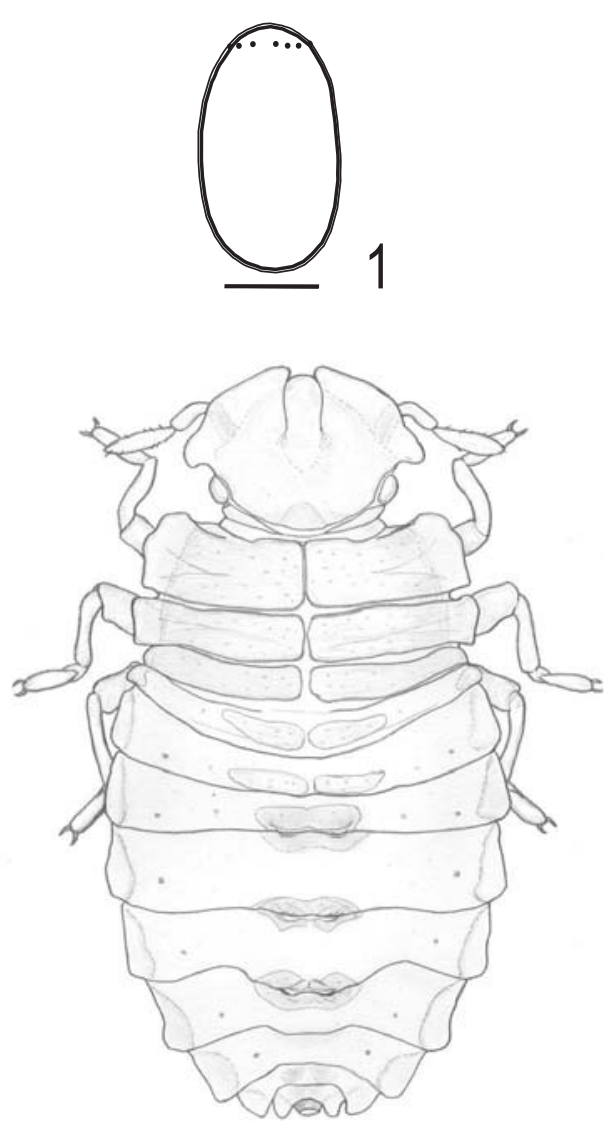

3
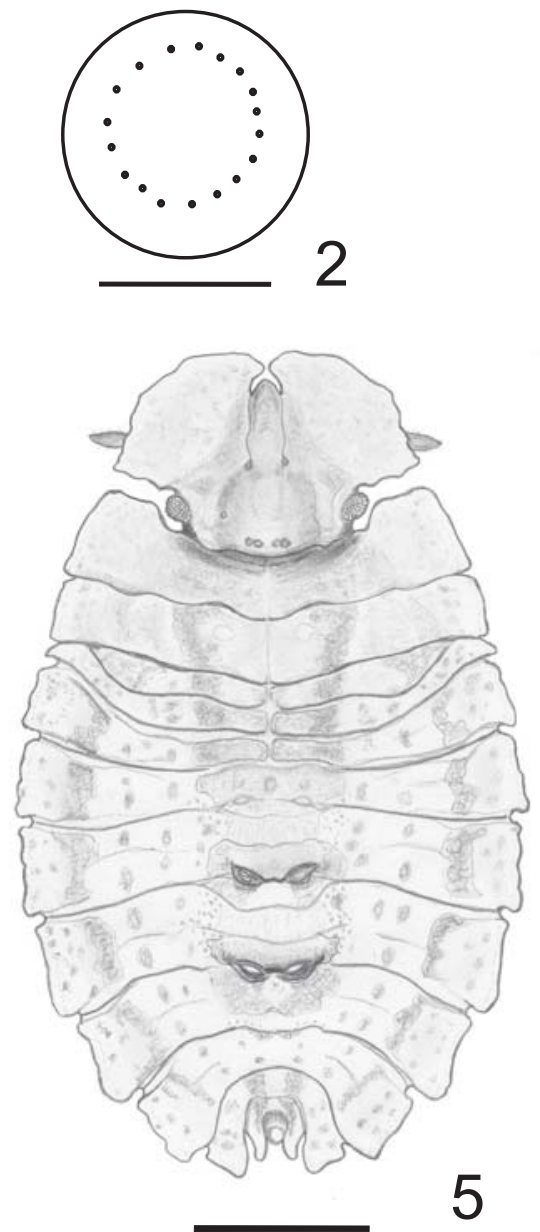

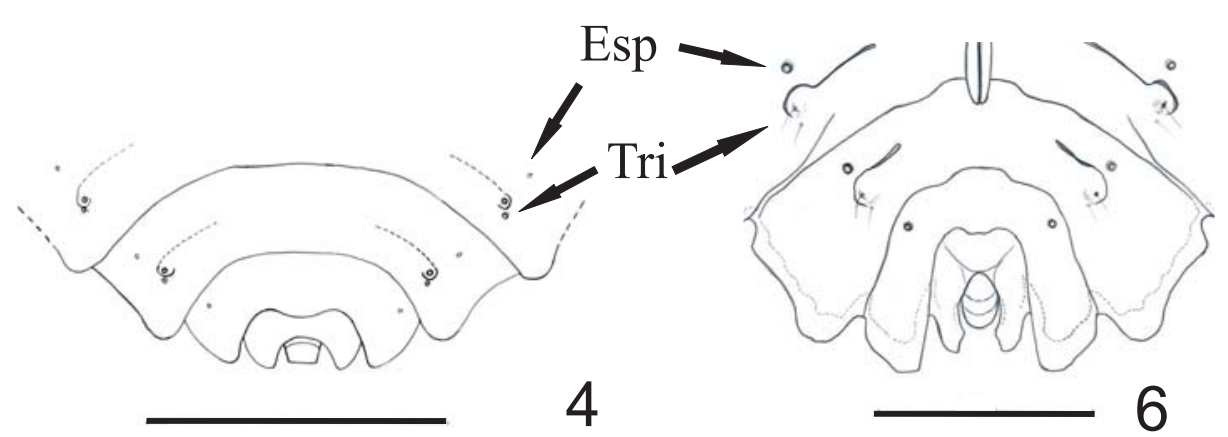

Figs. 1-6. Phloea subquadrata Spinola, 1837. Ovo: 1, lateral; 2, dorsal; 3, ninfa de $1^{\circ}$ instar, dorsal; 4, ápice do abdome da ninfa de $1^{\circ}$ instar, ventral; 5, ninfa de $2^{\circ}$ instar, dorsal; 6, ápice do abdome da ninfa de $2^{\circ}$ instar, ventral (Esp, espiráculo;Tri, tricobótrio). Escala, $1 \mathrm{~mm}$.

Tricobótrios (Fig. 8) com padrão semelhante ao instar anterior, circundados por uma pseudo-sutura enegrecida que separa os espiráculos do par de tricobótrios e continua em direção ao meio do urosternito.

Medidas (N = 6). CT, 9,23 - 9,72; CC, 2,28 - 2,52; CTO, 2,04 - 2,16; DI, 1,68 - 1,76; LA, 5,75 - 6,15; LT, 5,50 5,67 ; LC, 4,04 - 4,12; CR, 6,56 - 6,64; I, 0,80 - 0,88; II, 0,560,60; III, 0,76-0,80.

Quarto instar (Fig. 9). Muito semelhante ao adulto na forma. Coloração mais escura, resultante de maior concentração de pontuações e manchas. Bordo posterior do mesonoto trissinuado, evidenciando a formação das pterotecas, quase tão longas quanto o escutelo. Metanoto e segmento abdominal I abreviados lateralmente. Demais caracteres semelhantes aos do instar anterior.

Medidas (N=1). CT, 13,44; CC, 3,24; CTO, 2,91; DI, 2,02; LA, 7,93; LT, 7,29; LC, 5,42; CR, 6,88; I, 1,21; II, 0,81; III, 0,97 .

Quinto instar (Figs. 10-12). Apresenta grande desenvolvimento das expansões foliáceas cefálicas, 

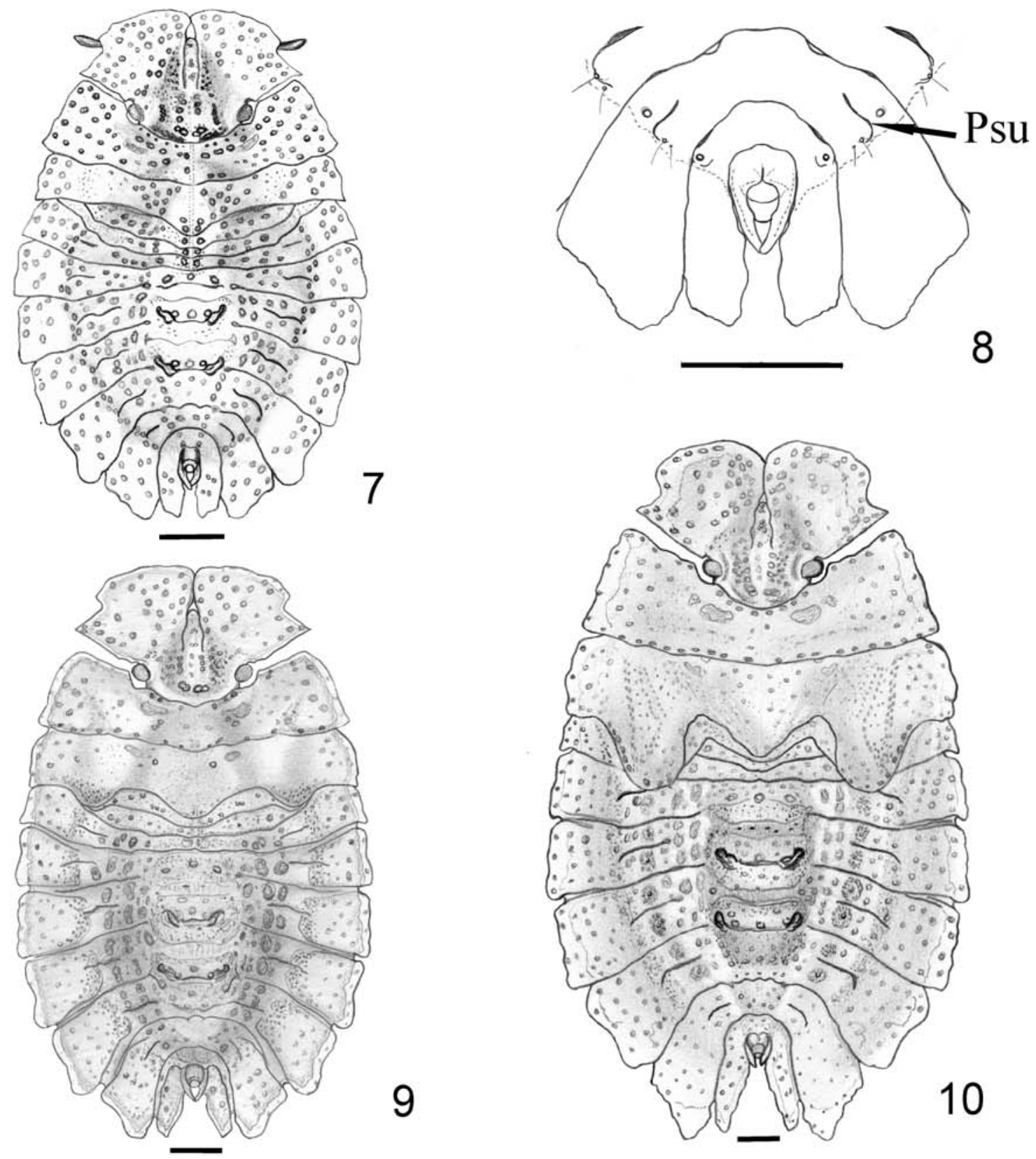

9
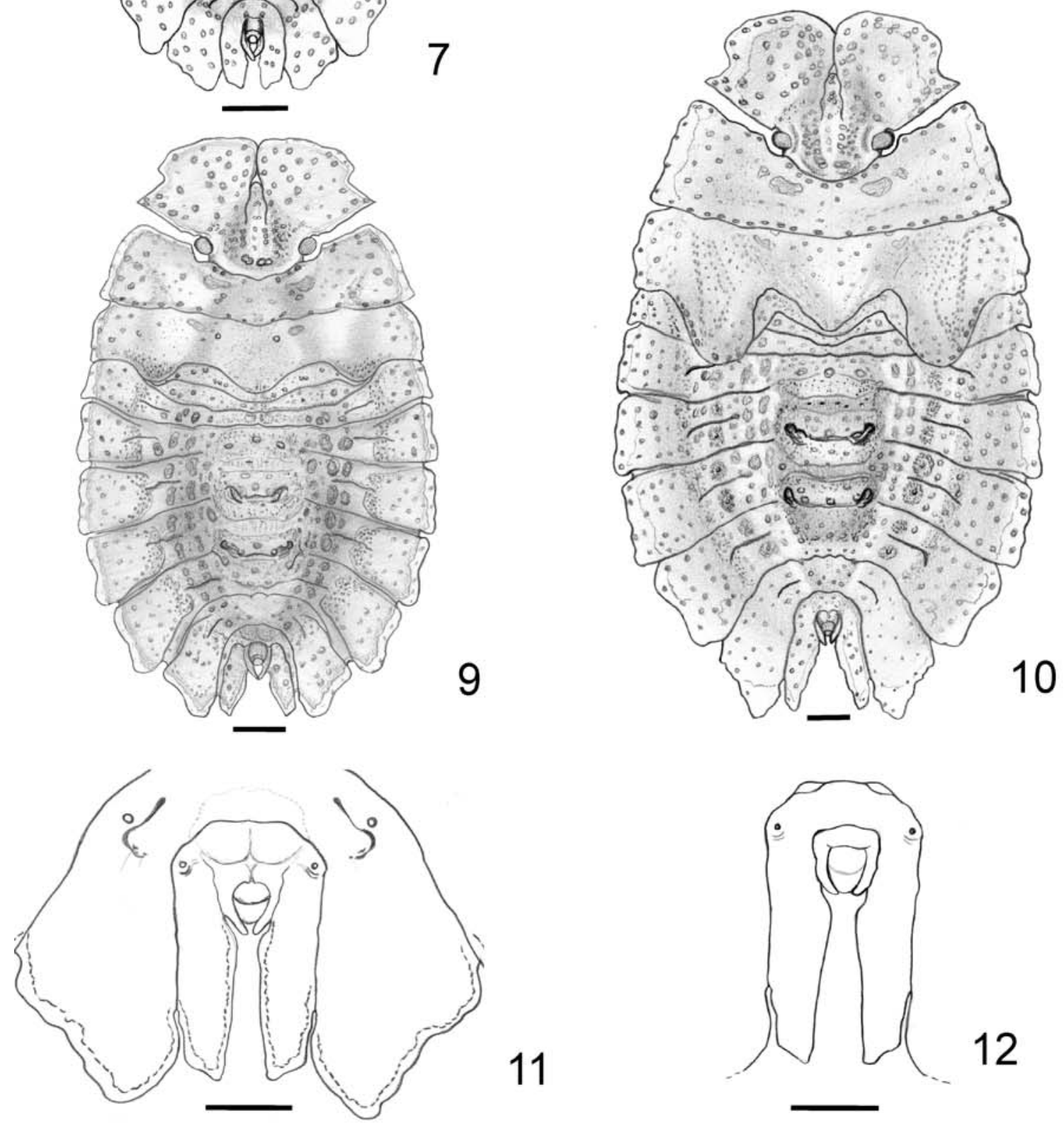

Figs. 7-12. Phloea subquadrata Spinola, 1837, morfologia externa das ninfas: 7, $3^{\circ}$ instar, dorsal; 8, $3^{\circ}$ instar, ventral, genitália externa indiferenciada, pseudo-sutura enegrecida que separa os espiráculos do par de tricobótrios; $9,4^{\circ}$ instar, dorsal; $5^{\circ}$ instar: 10, dorsal; 11 , genitália externa da fêmea, ventral; 12, genitália externa do macho, ventral (Psu, pseudo-sutura). Escala, 1mm. 
torácicas e abdominais (Fig. 10). Coloração como no adulto. Rostro ultrapassa as coxas metatorácicas. Pterotecas com o dobro do comprimento do escutelo, alcançam a pseudo-sutura do urotergito III. Espiráculos e tricobótrios como nos instares anteriores. Já é possível distinguir machos e fêmeas, como em muitos representantes da superfamília Pentatomoidea (GREVE et al. 2003; Matesco et al., 2003). Nas fêmeas, os urosternitos VIII e IX apresentam uma sutura longitudinal mediana (Fig. 11), ausente nos machos (Fig. 12).

Medidas ( $\mathrm{N}=6$ ). CT, 18,69 - 22,30; CC, 4,26 - 5,24; CTO, 4,42 - 6,06; DI, 2,29 - 2,78; LA, 10,00 - 12,62; LT, 9,67 - 11,80; LC, 6,72-8,36; CR, 7,93-10,20; I, 1,86-2,10; II, 1,131,$37 ;$ III, $1,13-1,37$.

No primeiro instar, as ninfas das espécies de Phloeidae são semelhantes quanto à forma geral e coloração. Entre as espécies já estudadas, as principais diferenças são o comprimento do rostro e o número de glândulas odoríferas dorsais. O rostro de Phloeophana longirostris é mais longo que o de Phloea subquadrata, atingindo o penúltimo segmento abdominal (LENT \& Jurberg, 1966). Além disso, Lent \& JuRberg (1966) encontraram apenas dois pares de glândulas em $P$. longirostris, entre os segmentos IV-V e V-VI. Essas variações mantêm-se nas ninfas dos instares posteriores, que diferem também em tamanho, formato dos bordos das expansões foliáceas e na coloração e textura características de cada espécie.

Biologia. Os espécimes coletados na Serra do Japi foram encontrados sobre Myrciaria jaboticaba (Vell.) O. Berg., "jaboticabeira", e Campomanesia guazumaefolia (Cambess.) O. Berg., "sete-capotes" (Myrtaceae). Em Viamão, os fleídeos foram observados em grandes agregados sobre Campomanesia xanthocarpa O. Berg., "guabiroba" e Campomanesia rhombea O. Berg., "guabirobinha" (Myrtaceae). As três espécies de Campomanesia constituem novos registros de planta hospedeira para $P$. subquadrata.

O estágio de ovo dura aproximadamente um mês e as ninfas independem da presença da fêmea para eclodir, como observado também para $P$. longirostris (LENT \& JURBERG, 1966). Em uma das posturas coletadas e mantidas em laboratório, ninfas eclodiram dos três ovos que não foram atacados por parasitóides. Na segunda postura observada, entretanto, os seis ovos intactos não se desenvolveram e sofreram dessecação. É possível, então, que a permanência da fêmea sobre a postura desempenhe um papel protetor também contra fatores abióticos.

As ninfas podem eclodir em dias diferentes, e observou-se no campo que as fêmeas podem abandonar a postura depois que a maioria dos imaturos eclodiu. Nestes casos, os ovos restantes podem ser viáveis ou não. Duas ninfas de primeiro instar foram registradas isoladas no tronco de Myrciaria jaboticaba, em janeiro e abril de 2004, e é provável que tenham eclodido após as posturas terem sido abandonadas.

As ninfas não se alimentam durante o primeiro estádio e permanecem presas na parte ventral do abdome da fêmea, que é côncava, até alguns dias após a primeira muda. A maneira com que aderem ao corpo ainda não foi estudada, mas pode estar relacionada à existência de uma substância viscosa observada no manuseio das ninfas.
Adicionalmente, os indivíduos de primeiro instar encontrados isolados não conseguiram fixar-se no caule após a manipulação.

Segundo GUILBERT (2003), a primeira muda ocorre em oito dias. O estágio ninfal, entretanto, é bastante longo. As ninfas observadas atingiram a idade adulta somente entre dezembro de 2004 e fevereiro de 2005 , levando de dez a doze meses para completar o desenvolvimento. A maior parte desse período transcorreu no terceiro ( $\bar{x}=143 \pm 62$ dias; $\mathrm{N}=117$ ) e quarto $(\bar{x}=129 \pm 35$ dias; $\mathrm{N}=39)$ estádios. É provável que as condições climáticas na estação fria e seca na Serra do Japi, coincidente com a época de ocorrência destes estádios (A. T. Salomão \& J. Vasconcellos Neto, dados não-publicados), influenciem diretamente a sua maior duração. Relações entre condições ambientais como temperatura, umidade e fotoperíodo (GULLAN \& CRANSTON, 1996) e o tempo de desenvolvimento de imaturos foram registradas para várias espécies de pentatomóideos tropicais (Torres et al., 1998; Chocorosqui \& PANIzZI, 2003; GREVE et al., 2003).

A magnitude dos desvios referentes à duração dos estádios pode resultar da ação de diferentes pressões seletivas sobre cada sexo, que podem levar a diferenças no tempo necessário para atingir o estágio adulto (STEARNS, 1997). Adicionalmente, alterações temporais na qualidade nutricional das plantas hospedeiras podem influir na duração de cada estádio (SCRIBER \& SLANSKY, 1981; Stearns, 1997). Neste estudo preliminar, entretanto, os indivíduos não foram sexados e a composição química das plantas não foi avaliada. Assim, mais estudos são necessários para entender a biologia e ecologia da espécie.

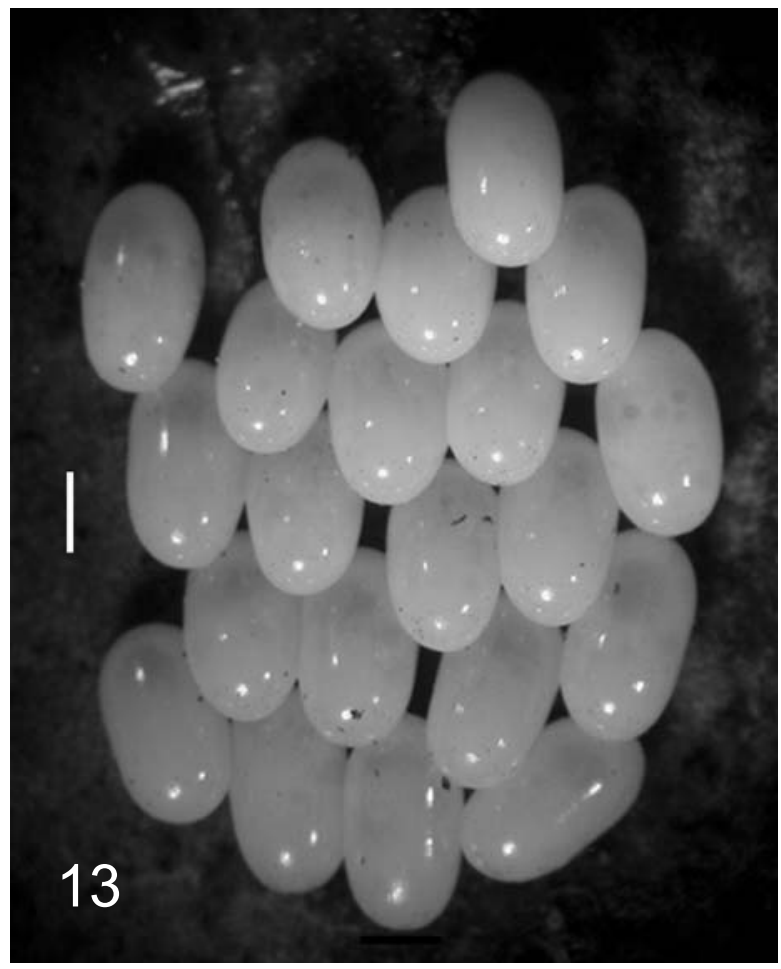

Fig. 13. Postura de Phloea subquadrata Spinola, 1837, aderida ao córtex de Campomanesia xanthocarpa (Myrtaceae). Escala, $1 \mathrm{~mm}$. 
Agradecimentos. Ao Dr. Paulo Brack e Anderson S. de Mello (UFRGS) e a Jorge Tamashiro (UNICAMP) pela identificação das plantas hospedeiras. Ao Pe. Albino Trevisan e ao Sr. Jalmirez R. da Silveira Jr. por possibilitar coletas no Colégio N. Sra. das Graças e aos funcionários da Base Ecológica da Serra do Japi pelo apoio logístico. Ao Dr. João Vasconcellos Neto, Luiz Fernando Martins e Augusto Ferrari (UNICAMP e UFRGS) pelo auxílio em campo, e a Cristiano F. Schwertner (UFRGS) pela elaboração das fotografias em laboratório. A Luciano de Azevedo Moura (FZBRS) pela leitura crítica do manuscrito. Ao CNPq e à FMB, pelas bolsas concedidas.

\section{REFERÊNCIAS BIBLIOGRÁFICAS}

Brailovsky, H.; Cervantes, L. \& Mayorga, C. 1992. Hemiptera: Heteroptera de Mexico XLIV. Biología, estadios ninfales y fenología de la tribu Pentatomini (Pentatomidae) en la Estación de Biología Tropical "Los Tuxtlas", Veracruz. Mexico, Universidad Nacional Autónoma de Mexico, Instituto de Biología. 204p. (Publicaciones especiales, 8)

Chocorosqui, V. R. \& Panizzi, A. R. 2003. Photoperiod influence on the biology and phenological characteristics of Dichelops melacanthus (Dallas, 1851) (Heteroptera: Pentatomidae). Brazilian Journal of Biology 63(4):655-664.

Greve, C.; Fortes, N. D. F. \& Grazia, J. 2003. Estágios imaturos de Oebalus poecilus (Heteroptera, Pentatomidae). Iheringia, Série Zoologia, 93(1):89-96.

Guilbert, E. 2003. Habitat use and maternal care of Phloea subquadrata (Hemiptera: Phloeidae) in the Brazilian Atlantic forest (Espirito Santo). European Journal of Entomology 100(1):61-63.

Gullan, P. J. \& Cranston, P. S. 1996. The insects: an outline of entomology. London, Chapman \& Hall. 491p.

Lent, H. \& Jurberg, J. 1965. Contribuição ao conhecimento dos Phloeidae Dallas, 1851, com um estudo sôbre genitália (Hemiptera, Pentatomoidea). Revista Brasileira de Biologia 25(2):123-144.
1966. Os estádios larvares de "Phloeophana longirostris" (Spinola, 1837) (Hemiptera, Pentatomoidea). Revista Brasileira de Biologia 26(1):1-4.

Leston, D. 1953. "Phloeidae" Dallas: systematics and morphology, with remarks on the phylogeny of "Pentatomoidea" Leach and upon the position of "Serbana" Distant (Hemiptera). Revista Brasileira de Biologia 13(2):121-140.

Matesco, V. C.; Fortes, N. D. F. \& Grazia, J. 2003. Imaturos de pentatomídeos (Hemiptera, Heteroptera): morfologia e biologia de Acrosternum obstinatum. Iheringia, Série Zoologia, 93(1):81-88.

RitcheR, P. O. 1972. Taxonomy of immature insects - present status and future needs. Bulletin of the Entomological Society of America 18:99-101.

Schun, R. T. \& Slater, J. A. 1995. True bugs of the World (Hemiptera, Heteroptera): classification and natural history. Ithaca, Cornell University Press. 336p.

Scriber, J. M. \& Slansky, F., JR. 1981. The nutritional ecology of immature insects. Annual Review of Entomology 26: $183-211$.

Stearns, S. C. 1997. The evolution of life histories. Oxford, OUP. 249 p.

Stehr, F. W. 1991. Immature insects. Dubuque, Kendall/Hunt. v. $2,974 \mathrm{p}$.

Tallamy, D. W. \& Schaefer, C. 1997 Maternal care in the Hemiptera: ancestry, alternatives, and current adaptative value. In: Choe, J. C. \& Crespi, B. J. eds. The evolution of social behavior on insects and arachnids. Cambridge, CUP. p.94-115.

Torres, J. B.; Zanuncio, J. C. \& Oliveira, H. N. De. 1998. Nymphal development and adult reproduction of the stinkbug predator Podisus nigrispinus (Het., Pentatomidae) under fluctuating temperatures. Journal of Applied Entomology 122(910):509-514.

Wolf, K. W.; Reid, W. \& Rider, D. A. 2002. Eggs of the stinkbug Acrosternum (Chinavia) marginatum (Hemiptera, Pentatomidae): a scanning microscopy study. Journal of Submicroscopic Cytology and Pathology 34(2):142-149. 